\section{Still more about AIDS}

SIR - G. Garnett and R. Anderson (Nature 366, 716; 1993) state that Duesberg's claim that drug use rather than HIV is the cause of AIDS has been firmly rejected, but we do not agree. They rely in part on the Vancouver study (Lancet 13 March 1993) but Duesberg has pointed out that that study does not provide controls (verified drug-free AIDS cases), does not quantify drug use and ignores Zidovudine use.

Garnett and Anderson also refer to one of us (J.S.) as a "television presenter" and use the phrase "non-expert opinion". J. S. has specialized in AIDS issues for seven years, and has made seven television documentaries analysing scientific knowledge about AIDS.

Our work in preparing for the British network television documentary referred to involved consulting expert opinion from all the countries we visited as well as that of our special consultant Dr Harvey Bialy. The remarks by Garnett and Anderson about Bialy are totally unjustified. Bialy spent six years working in West Africa on the epidemiology of plasmidmediated antibiotic resistance among enteric pathogens, and in recent years has travelled extensively in Africa for WHO, UNESCO and UNIDO. He is an acknowledged expert on the implementation of biotechnology in Africa and has a wide knowledge of biotechnology-produced diagnostic tests.

\section{Joan Shenton}

Volker Gildemeister

Meditel,

Bedford Chambers,

The Piazza, Covent Garden,

London WC2E 8HA, UK

This letter was submitted to the Sunday Times on 16 December 1993 but was not published.

SIR - The truth about AIDS is to be found in the overall consensus, gained over years of research. This is the approach we take in studying any disease - not by homing in on one or two unusual or anecdotal reports, which has been the hallmark of the Sunday Times coverage of AIDS. Let us look at assertions made in the article "AIDS - why we won't be silenced" (12 December 1993).

- US infection rates at 1 million are stable _- "a new or mutant virus does not behave in this way". This is an odd statement. Infection rates rose rapidly in the mid1980 s in every group studied, as in the United Kingdom. Levels are stable now because the number dying of AIDS each year in the United States (more in 1993 than died in the entire Vietnam War) is now the same as the number of new infections. The rest can be explained by saturation effects in high-risk groups and behavioural change. African and Asian infection rates have risen rapidly too.

at is true that almost all these deaths will be among homosexual men or drug abusers, many of whom are black. If, as some suggest, these deaths will have little impact, then that is a terrible reflection on an intolerant society rather than saying anything about the dangers of HIV and AIDS.

a "In every patient studied so far there is never more than one in 1,000 cells infected with HIV'. Out of date. There are high levels of HIV-infected cells in lymph nodes, even in early infection.

- "Many healthy people have co-existed harmlessly with HIV for many years." Of course they have. This is a slow virus, but to survive with HIV longer than 15 years without signs of illness or immune damage is very rare.

"Even Luc Montagnier, who discovered HIV, has argued that microbes called mycoplasma, which he now knows to have been present in his original 'AIDS virus' culture, are the chief cause of the death of the immune cells in AIDS patients." Again, nonsense. No one gets AIDS from mycoplasma alone. Mycoplasma infection is very common in the general population.

" "The evidence HIV causes AIDS is still epidemiological." Of course. How else can one find a link? For the link between smoking and cancer, we accept such evidence as valid, and rightly so - why the double-think when it comes to AIDS?

a People with HIV die of AIDS, those with no HIV do not. Those with haemophilia, or those who inject drugs with shared needles, or homosexual men can be separated into two groups on the basis of an HIV test. Identical in all other respects, one groups becomes ill and dies with AIDS, the other remains healthy.

It is true that out of thousands of cases of severe immune deficiency studied, very occasionally someone has been found with an illness that looks like AIDS in the absence of HIV. So what? Doubting the HIV link on that basis is as stupid as saying that, because lung cancer can happen in non-smokers, smoking does not cause lung cancer.

We are told that haemophiliacs with HIV who have converted to using purified blood products "have recovered fully. and there now seems no reason why they should not have a normal lifespan". There is no evidence to support such a wild statement.

Finally, we are presented with a paper in Bio/technology claiming that a high proportion of those testing HIV positive in Africa are "false positives because of the inadequacies of the test". It is a pity that no one at the Sunday Times bothered to check the paper's references. If they had, they would have found that the evidence of false positives is dated almost entirely from the mid-1980s, using the very first primitive tests for HIV. These did have high false positive rates, unlike the tests used for the past few years.

Recently, a Sunday Times banner headline read "African AIDS Plague a Myth". This sensational story was based on a conversation with a pair of charity workers in Tanzania, neither of whom is a doctor or scientist. Their anecdotal accounts were presented as fact, while local experts were ignored. Their credibility is very low in Tanzania. The misquotation from Dr Timothy Stamps of the Department of Health in Zimbabwe, apparently supporting the 'AIDS myth' theory, was wildly misleading and poor journalism, as he is well known for his view that AIDS is a serious threat in Africa and elsewhere.

How can you write off the whole African AIDS epidemic as a "myth" when six out of ten women with AIDS in London are from African nations, infected abroad - the visible edge of a huge epidemic? Most specialists are convinced that 90 per cent of new infections are heterosexually transmitted worldwide, more than half among women.

I am convinced that each one of these poorly researched stories has cost lives. You have created confusion and encouraged carelessness. I am all for balanced scientific debate but this, quite simply, is poor, but dangerous, journalism.

\section{Patrick Dixon}

AIDS Care Education and Training,

POBOX 1323,

London W5 5TF, UK

\section{Poverty not a cause}

SIR - In commenting on India's latest earthquake (Nature 365, 476; 1993) you emphasized that it was not the earthquake per se but poverty that killed people. However, instead of revealing the underlying socio-economic and political dynamics of poverty along the lines of seismic mechanisms of earthquakes, the discussion was devoted to the ramifications of poverty and their ill-effects. Why only earthquakes? Scientists are equally fond of blaming poverty for a similar role in flood, famine and epidemics such as AIDS. But where does poverty come from, and who perpetuates it? Unless such questions become part of scientific discourse, poverty will continue to be construed as a 'cause' rather than a 'product', and its resolution will remain elusive.

\section{R. Murmu}

Department of Surgery,

All India Institute of Medical Science,

NewDelhi-110029,

India 